\title{
Age differences in the potentiation of taste aversion by odor cues
}

\author{
CINDY S. PETERSON, WILLIAM A. VALLIERE, and JAMES R. MISANIN \\ Susquehanna University, Selinsgrove, Pennsylvania
}

and

\author{
CHARLES F. HINDERLITER \\ University of Pittsburgh at Johnstown, Johnstown, Pennsylvania
}

\begin{abstract}
The potentiation of a conditioned aversion to saccharin by maple odor was examined in a latent inhibition paradigm using weanling, young-adult, and old-age rats. Potentiation of the flavor aversion was age-related. There was a potentiation effect only in young-adult rats. These results are discussed in terms of current explanations of potentiation. It is suggested that when the components of a compound stimulus are in different systems, that is, interoceptive-exteroceptive, conditioning occurs in both systems and one system enhances conditioning in the other. This could explain the apparent reciprocal potentiation in odor/taste pairings as well as age differences in potentiation.
\end{abstract}

Several studies have shown that odor is a relatively ineffective CS when an illness-inducing agent is the US (Garcia \& Koelling, 1967; Hankins, Garcia, \& Rusiniak, 1973). More recently, however, researchers have demonstrated that odor can become not only an effective cue but even a potent cue for illness if it is paired with taste cues at the time the illness-inducing agent is administered (Durlach \& Rescorla, 1980; Rusiniak, Hankins, Garcia, \& Brett, 1979). Rusiniak et al. (1979) maintain that potentiation is due to taste's facilitating the formation of an association between the normally ineffective CS, odor, and illness. Durlach and Rescorla (1980), on the other hand, suggest that potentiation of conditioning to the weak odor cuè is due to within-compound learning, that is, an association between odor and an aversive taste. Although the majority of the research on potentiation has neither examined nor emphasized reciprocity-that odor cues paired with taste cues at the time of illness may also potentiate a conditioned aversion to taste-the explanations clearly do not preclude such potentiation.

Two recent studies that did attempt to determine if odor reciprocally potentiates conditioned taste aversion did not yield consistent results. One investigation (Westbrook, Homewood, Horn, \& Clarke, 1983) found that odor attenuated (overshadowed) taste aversion, whereas the other found potentiation (Spear \& Kucharski, 1984). Perhaps conditioned taste aversion, particularly in adult rats, is generally so intense that there is little opportunity for odor, a weak cue for illness, to potentiate the aversion. The purpose of the present study was, therefore, to determine if

This research was supported in part by a Summer Research Grant from Susquehanna University to James R. Misanin. Reprint requests should be addressed to James R. Misanin, Department of Psychology, Susquehanna University, Selinsgrove, PA 17870. odor would potentiate taste aversion under conditions in which the conditioned aversion to taste would normally be retarded, that is, following CS preexposure. Accordingly, we investigated the potentiation effect within the context of latent inhibition (Lubow \& Moore, 1959), or "learned safety" (Kalat \& Rozin, 1973). Since the ease of establishing a taste cue as a latent inhibitor has been shown to be inversely related to age (Misanin, Blatt, \& Hinderliter, 1985), the potentiation effect was examined in weanling, young-adult, and old-age rats.

\section{METHOD}

\section{Subjects}

Forty Wistar-derived albino rats at each of three age levels, randomly selected from animals born and reared in the university animal colony, were the subjects in this experiment. The age levels were weanling (20-25 days), young adult (145-155 days), and old age (800-840 days). The animals were housed in standard suspended galvanized rodent cages.

\footnotetext{
Apparatus

All drinking sessions occurred in cages that were similar to home cages except that the drinking cages were equipped with four springgrip clamps to hold cylinders and a 25-mm-diam metal cap that contained a cotton ball on which $.1 \mathrm{ml}$ of Wagner's Artificial Maple Flavor was placed. The cap, which was out of the reach of the subject, was situated $3 \mathrm{~cm}$ below the sipper tube of a $100-\mathrm{ml}$ cylinder (graduated to $1 \mathrm{ml}$ ) that was located at the center of the front of the cage. The other two clamps on the front of the cage, located $35 \mathrm{~mm}$ from each side, were used to hold two graduated $100-\mathrm{ml}$ cylinders on the test day. All drinking sessions and treatments took place in the same room in which the animals were normally housed. However, on the days odor was to be presented, to prevent inadvertent exposure to the maple odor, all animals were housed in another room and returned there until $30 \mathrm{~min}$ after the treatments were completed. There was a complete air exchange every $20 \mathrm{~min}$ in the room where the drinking sessions and treatments took place, and there were no apparent odor traces when the animals were returned to this room.
} 


\section{Procedure}

Initially, the animals were deprived of water for $23 \mathrm{~h}$. Following two daily adaptation sessions, during which the animals were given 1-h access to room-temperature tap water in the drinking cages, four groups ( $\mathrm{N}=8$ /group) at each age level were given two daily 1 -h preexposure sessions (preexposed groups). Preexposure consisted of access to $.1 \%$ (w/v in tap water) saccharin solution and simultaneous exposure to maple odor. An additional group of eight animals at each age level experienced neither the maple odor nor the saccharin solution during these sessions but had access to water (nonpreexposed groups). The day following the last preexposure session, a conditioning or a nonconditioning trial was given. A conditioning trial consisted of 10-min access to the CS (maple odor and/or .1\% saccharin solution) followed immediately by a $1 \%$ body weight ip injection of $.15 \mathrm{M} \mathrm{LiCl}$. For the nonconditioning trial, a comparable injection of $.9 \% \mathrm{NaCl}$ (saline) replaced the $\mathrm{LiCl}$ injection. The four preexposed groups at each age level were treated differentially. The potentiation experimental group received an odor/taste $\mathrm{LiCl}$ pairing. The potentiation control group received a taste- $\mathrm{LiCl}$ pairing. The within-compoundlearning control group received an odor- $\mathrm{LiCl}$ pairing. The nonconditioned control group received an odor/taste-saline pairing. The remaining nonpreexposed control group received an odor/saccharin$\mathrm{LiCl}$ pairing. Twenty-four hours after the conditioning or nonconditioning trial, the animals were given a 24-h two-bottle (saccharin vs. water) test. The amount of each solution consumed was recorded at $1,6,18$, and $24 \mathrm{~h}$.

\section{RESULTS}

The amount (in milliliters) of each solution consumed at each of the four access times was computed for each rat and converted to a preference score [saccharin/(saccharin + water)] $\times 100$. The preference scores were then averaged for groups. Group results are depicted in Figure 1 . With the significance level set at .05 , a split-plot factorial analysis of variance performed on the preference data yielded a significant age $\times$ treatment interaction $[F(8,105)=4.66]$ and a significant main effect of access time $[\mathrm{F}(3,315)=12.3]$. Individual comparisons showed that all conditioned groups preexposed to the maple odor/ saccharin compound, that is, odor/taste- $\mathrm{LiCl}$ (potentiation experimental), taste/ $\mathrm{LiCl}$ (potentiation control), and odor- $\mathrm{LiCl}$ (within-compound learning control), had a greater preference for saccharin than did the nonpreexposed controls, indicating a preexposure effect (latent inhibition) at all age levels $[\mathrm{Fs}(1,105)>8.54]$. The within-compound learning control group at each age level failed to differ from its respective saline control group, indicating no within-compound learning effect. Comparisons between the potentiation controls and the saline controls at each age level indicated that preexposure to the odor/taste compound eliminated taste aversion conditioning in weanlings and young adults $[\mathrm{Fs}(1,105)<.05]$ but only retarded taste aversion conditioning in old-age animals $[F(1,105)=32.21]$. Comparisons between the potentiation experimental and potentiation control groups at each age level showed a significant difference at the young-adult level $[\mathrm{F}(1,105)=9.51]$ but not at the weanling and old-age levels $[\mathrm{Fs}(1,105)<2.70, \mathrm{p}>.10]$. Thus, only for the young adults did odor retard latent inhibition, that is, potentiate the aversion to saccharin.

\section{DISCUSSION}

The results of the present study indicate that maple odor potentiates an illness-induced aversion to saccharin in young-adult rats but not in weanling and old-age rats.

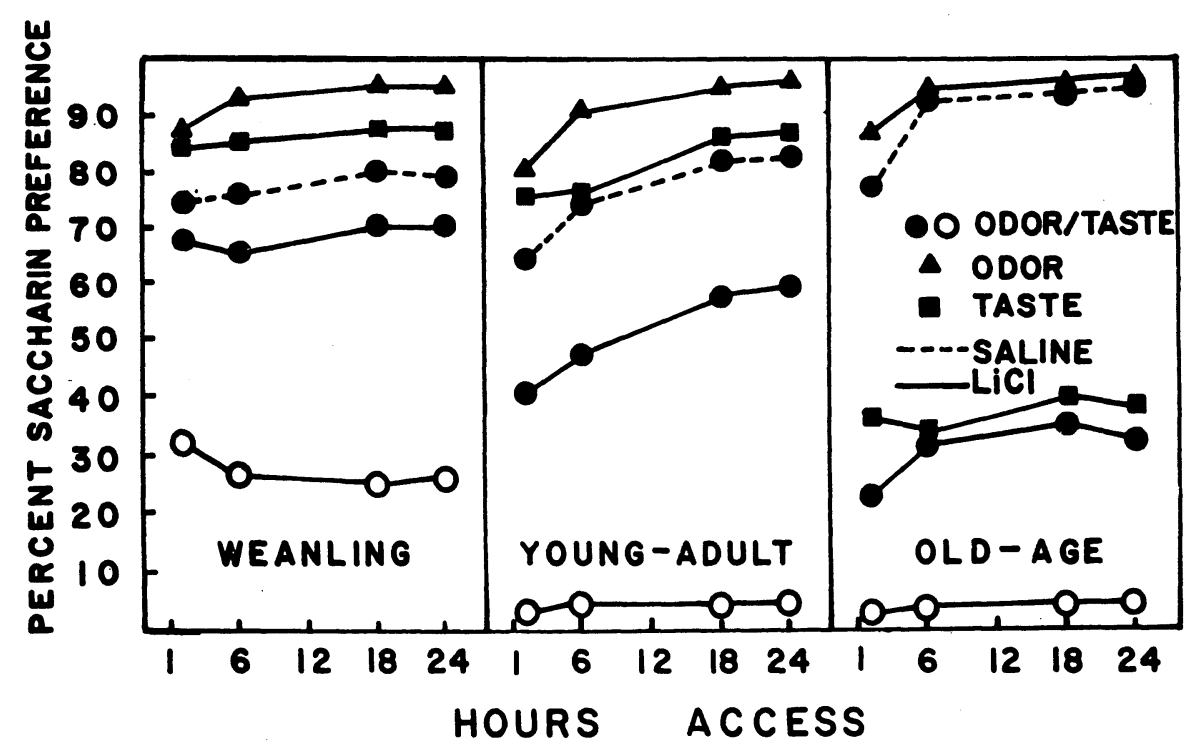

Figure 1. Mean percent preference for saccharin as a function of age, preexposure condition, conditioning treatment, and hours of access. Open circles depict nonpreexposed groups, and filled circles depict groups preexposed to the odor/taste compound. Of the four preexposed groups, one (potentiation experimental, - - received an odor/taste- $\mathbf{L i C l}$ pairing, another (potentiation control, $\square$ ) received a taste- $\mathrm{LiCl}$ pairing, a third (within-compound learning control, $\Delta$ ) received an odor-LiCl pairing, and the fourth (nonconditioned control, ---) received an odor/taste $\mathrm{NaCl}$ pairing. The nonpreexposed control $(O)$ received an odor/taste- $\mathrm{LiCl}$ pairing. 
Aside from these age differences, the potentiating effect of an odor on conditioned taste aversion is interesting for a number of reasons. First, potentiation per se, from a theoretical view, is an unexpected phenomenon. Most theories of conditioning predict that when two stimuli are presented as a compound CS, less conditioning should accrue to each stimulus than would accrue if each stimulus were presented alone (overshadowing). Second, current explanations of potentiation fail to adequately explain the present results. Durlach and Rescorla (1980), for example, maintain that within-compound associations are responsible for potentiation. According to this view, the weaker CS component can gain strength from the stronger or more salient component, that is, the weaker component takes on aversive properties not only because of its association with the illness-inducing agent, but also because of its association with the stronger or more salient CS component which is inherently aversive or which has taken on highly aversive properties due to its salient character and its pairing with the aversive US. In our experiment, however, it was the aversion to the stronger cue for illness, saccharin, that was potentiated by the weaker cue, odor. And, when odor alone was paired with $\mathrm{LiCl}$, there was no aversion to saccharin, even though the odor had been previously paired with saccharin. Thus, it is unlikely that within-compound associations can account for the observed potentiation of saccharin aversion. Although Rusiniak's et al. (1979) associative potentiation hypothesis could be amended to incorporate the present results, since weanlings typically form poorer associations than adults in flavor-aversion situations (Baker, Baker, \& Kesner, 1977; Martin \& Timmins, 1980; Misanin et al., 1985), their interpretation in terms of the adaptive nature of potentiation seems to gain little support from the present results. These investigators suggested that potentiation is adaptive in the sense that it permits a species to use telereceptors to avoid a poisoned food at a distance. In our experiment, it was the distal odor cue that potentiated the aversion to the proximal taste cue; this would seem to have little, if any, adaptive value. It would appear that potentiation is a more general phenomenon than that suggested by Rusiniak et al. (1979) and its adaptive nature in some cases is, for the most part, fortuitous.

However, the potentiation we observed disagrees with the results of recent research by Westbrook et al. (1983). These investigators found (Experiment I) that when taste potentiated an odor aversion, the odor attenuated the flavor aversion. There are so many procedural differences between their research and ours that it is impossible to specify the factors responsible for the discrepant findings. Westbrook et al. used a one-bottle test and flavors (quinine and hydrochloric acid) that are relatively aversive compared with the saccharin used in the present study, and, unlike us, they did not preexpose their animals to the odortaste compound. Westbrook et al. also found that the potentiation effect is governed by the duration of exposure to the compound, with long exposure being conducive to potentiation. Thus, the relatively long preexposure to the compound that we used may have been conducive to the potentiation we observed.

More recently, Spear and Kucharski (1984) did find potentiation of a taste aversion by odor. Our results, however, also seem to disagree with theirs, which showed that potentiation is greater in infant rats than in young adults. Our results showed the opposite. This discrepancy may also be due to differences in procedure-for example, Spear and Kucharski used preweanling rats whereas we used weanling rats in the present study. Also, Spear and Kucharski did not give their animals preexposure to the components of the CS. It is possible that CS preexposure in the present study weakened the effectiveness of both odor and flavor as a CS more for weanling rats than for adults. Misanin et al. (1985) have, in fact, shown that preexposure to a flavor-CS-to-be weakens its effectiveness more for weanlings than for adults. Alternatively, Lett (1984) has suggested that the potentiation effect following preexposure is different from that observed when animals have not previously experienced the components of the CS. Thus, the discrepancy between our results and those of Spear and Kucharski, as well as the discrepancy between our results and those of Westbrook et al. (1983), may be due to our studying a different phenomenon.

Spear and Kucharski's (1984) interpretation of potentiation attempts to explain when potentiation rather than overshadowing will occur. According to these investigators, weanling animals, in contrast to adults, show potentiation because they fail to dissociate the components of the compound CS, that is, they perceive the compound as an integral whole, and, in effect, are subjected to a more "intense"' CS, which results in greater conditioning. The multiple preexposures to the CS-to-be in our experiment may have resulted in our young-adult animals' forming associations that would result in their perceiving the CS as an integral whole, and, since young adults form stronger associations in a flavor aversion situation than do weanlings, the potentiation effect was observed only in these animals. Although this is an attractive hypothesis, it is difficult to delineate the conditions that will lead animals of different ages to perceive a compound stimulus as an integral whole. Spear and Kucharski (1984) suggested that potentiation rather than overshadowing is the more basic phenomenon and that overshadowing should increase with age. Our results suggest that the relationship between age and strength of potentiation is a curvilinear relationship.

In the majority of cases in which potentiation has been demonstrated (Clarke, Westbrook, \& Irwin, 1979; Durlach \& Rescorla, 1980; Galef \& Osborne, 1978; Lett, 1984; Rusiniak et al., 1979; Westbrook et al., 1983), one of the components of the compound CS has been an exteroceptive stimulus and the other an interoceptive stimulus. Reports of potentiation when both elements of the compound have been interoceptive (Bouton \& Whiting, 1982; Kucharski \& Spear, 1985) have not been consistent. In one study in which potentiation resulted when both components of the CS were reported to be interoceptive 
stimuli (e.g., coffee/sucrose in Kucharski \& Spear, 1985), one (coffee) had an exteroceptive (odor) component. Although there may be some debate over the system to which odor belongs, research has shown that it functions primarily as an exteroceptive stimulus (Hankins, Rusiniak, \& Garcia, 1976). Thus, it may be that potentiation occurs when the components of the CS are in different systems and overshadowing occurs when they are in the same system. It may be that full conditioning accrues to each component when they are in different systems and each system enhances or potentiates conditioning in the other. This would explain the apparent reciprocal potentiation in odor/ taste-illness pairings and may account for age differences in potentiation. Age differences in potentiation may be due to age differences in system efficiency.

\section{REFERENCES}

BAKer, L. J., BAKer, T. B., \& Kesner, R. P. (1977). Taste aversion learning in young and adult rats. Journal of Comparative \& Physiological Psychology, 91, 1168-1178.

Bouton, M. E., \& Whiting, M. R. (1982). Simultaneous odor-taste and taste-taste compounds in poison-avoidance learning. Learning \& Motivation, 13, 472-494.

Clarke, J. C., Westbrook, R. F., \& Irwin, J. (1979). Potentiation instead of overshadowing in the pigeon. Behavioral \& Neural Biology, 25, 18-29.

Durlach, P. J., \& Rescorla, R. A. (1980). Potentiation rather than overshadowing in flavor-aversion learning: An analysis in terms of within-compound associations. Journal of Experimental Psychology. Animal Behavior Processes, 6, 175-187.

GALEF, B. G., \& OsBorne, B. (1978). Novel taste facilitation of the association of visual cues with toxicosis in rats. Journal of Comparative \& Physiological Psychology, 92, 907-916.
Garcia, J., \& Koelling, R. A. (1967). A comparison of aversions induced by X-rays, toxins, and drugs in the rat. Radiation Research Supplement, 7, 439-450.

Hankins, W. G., Garcia, J., \& Rusiniak, K. W. (1973). Dissociation of odor and taste in baitshyness. Behavioral Biology, 8, 407-419.

Hankins, W. G., Rusiniak, K. W., \& Garcia, J. (1976). Dissociation of odor and taste in shock-avoidance learning. Behavioral Biology, 18, 345-358.

Kalat, J. W., \& Rozin, P. (1973). "Learned safety" as a mechanism in long-delay taste aversion learning in rats. Journal of Comparative \& Physiological Psychology, 83, 198-207.

KUCHARSKI, D., \& SPEAR, N. E. (1985). Potentiation and overshadowing in preweanling and adult rats. Journal of Experimental Psychology: Animal Behavior Processes, 11, 15-34.

LETT, B. T. (1984). Extinction of taste aversion does not eliminate taste potentiation of odor aversion in rats or color aversion in pigeons. Animal Learning \& Behavior, 12, 414-420.

Lubow, R. E., \& Moore, A. U. (1959). Latent inhibition: The effect of non-reinforced pre-exposure to the conditioned stimulus. Journal of Comparative and Physiological Psychology, 52, 415-419.

MarTin, G. N., \& Timmins, W. K. (1980). Taste-sickness associations in young rats over varying delays, stimulus and test conditions. Animal Learning \& Behavior, 8, 529-533.

Misanin, J. R., Blatt, L. A., \& Hinderliter, C. F. (1985). Age dependency in neophobia: Its influence on taste-aversion learning and the flavor-preexposure effect in rats. Animal Learning \& Behavior, 13, 69-76.

Rusiniak, K. W., Hankins, W. G., Garcia, J., \& Brett, L. P. (1979). Flavor-illness aversions: Potentiation of odor by taste in rats. Behavioral \& Neural Biology, 25, 1-17.

SPEAR, N. E., \& KUCHARSKI, D. (1984). Ontogenetic differences in the processing of multi-element stimuli. In R. Kail \& N. E. Spear (Eds.), Memory development: Comparative perspectives. Hillsdale, NJ: Erlbaum.

Westbrook, R. F., Homewood, J., Horn, K., \& Clarke, J. C. (1983). Flavour-odour conditioning: Odour potentiation and flavour attentuation. Quarterly Journal of Experimental Psychology, 35B, 13-33. 